\title{
Seasonal variation in the occurrence of the medicinal leech Hirudo orientalis in Guilan Province, Iran
}

\author{
K. Darabi-Darestani, M. Malek* \\ University of Tehran, School of Biology, College of Science, University of Tehran, Tehran, Iran
}

\begin{abstract}
Two small populations of medicinal leeches Hirudo orientalis Utevsky \& Trontelj, 2005 were sampled monthly over the course of a year (November 2008 to October 2009) in 2 separate regions of Guilan Province in northern Iran. Environmental factors, including host availability, temperature and vegetation density (biomass in $\mathrm{g} \mathrm{km}^{-2}$ ) were analyzed to assess their impact on leech populations. The study areas supported only low densities (ind. $\mathrm{km}^{-2}$ ) of medicinal leeches, mostly due to agricultural activity which has caused habitat destruction and has gradually limited the distribution of leeches to small, patchy bodies of water. Agricultural activity is seasonal, so leeches are not affected by this activity equally year round. Leeches were most abundant in May/June, were present in small numbers in July/August, and hibernated from December to March 2009 at both sites. Leech density was significantly correlated with amphibian density (biomass in $\mathrm{g} \mathrm{km}^{-2}$ ), the major hosts in the sample areas. Temperature and aquatic vegetation densities affected leech numbers directly (temperature influencing leech growth rate and vegetation providing shelter from potential predators) and indirectly (due to the impact of temperature and vegetation on the amphibian population, the leeches' major prey). Leeches of $<1 \mathrm{~g}$ were found mostly in April and May following hatching, while those $>5 \mathrm{~g}$ were predominant in September.
\end{abstract}

KEY WORDS: Seasonal variation · Environmental factors · Population density · Hirudo orientalis · Iran

Resale or republication not permitted without written consent of the publisher

\section{INTRODUCTION}

Throughout nearly 2000 yr of documented history, the medicinal leech Hirudo medicinalis L. has received considerable attention in various fields of human activity. Its ectoparasitic, haematophagous feeding habit has been used and misused for medicinal purposes for centuries (Utevsky \& Trontelj 2005). H. medicinalis was considered endangered by the Convention on International Trade in Endangered Species of Wild Fauna and Flora (CITES) in 1987 (see Kasparek et al. 2000). Utevsky \& Trontelj (2005) regarded $H$. medicinalis as the best-studied leech species, but only limited work has been carried out to determine seasonal variation in its occurrence (Wilkin \& Scofield, 1991, Demirsoy et al. 2001, Kalniņš 2006). The growth of the medicinal leech $H$. medicinalis L. was studied in the wild using a mark and recapture technique and in the laboratory (Wilkin \& Scofield 1991). Hirudinea in China were reviewed in Enguang (2008), and the ecological distribution of Hirudinea, the population dynamics of $H$. hainana, the adaptation of $H$. hainana to temperature, soil humidity and $\mathrm{pH}$, the response of $H$. hainana to temperature, relative humidity and light, and the effects of human activities on $H$. hainana populations have been discussed (Enguang 2008). H. orientalis Utevsky \& Trontelj, 2005, another medicinal leech, is similar in appearance to $H$. medicinalis L. Recent molecular systematic research (Trontelj et al. 2004, Trontelj \& Utevsky 2005) confirmed the validity of the taxonomic classification of 2 previously neglected species, $H$. verbana Carena, 1820 and $H$. troctina (Johnson, 1816), and suggested that a different variety from Transcaucasia, Iran and Uzbekistan is a new species (Utevsky \& Trontelj 2005). Grosser \& Pešić (2006) formally described the medicinal leech $H$. orientalis found in Mazandaran Province, Noshahr, Iran. There is little information available on $H$. orientalis, but, as it is in high demand for medicinal purposes and collected from this and other regions 
in large numbers (K. Darabi-Darestani pers. obs.), it may also be endangered. Although there is no published data to support this assumption, leech farming would be a good solution to avoid over-exploitation of leeches should they indeed be endangered. Currently, there is no documentation on the seasonal distribution of $\mathrm{H}$. orientalis. The aim of the present study was to examine 2 small populations of $H$. orientalis and to determine the effects of environmental factors on seasonal fluctuation in life stage and numbers.

\section{MATERIALS AND METHODS}

Study area. To study seasonal variation in the occurence of Hirudo orientalis, 2 populations were selected in Guilan Province, northern Iran (Fig. 1). The first sample site near the city of Rasht $\left(37^{\circ} 16^{\prime} \mathrm{N}\right.$, $49^{\circ} 36^{\prime}$ E), consisted of 4 areas of shallow still waters (2.0 to $4.5 \mathrm{~m}$ depth) with a total surface area of $2 \times$ $2.8 \mathrm{~km}^{2}$. These patchy bodies of water are near rice fields and support freshwater life throughout the year. Their water supply comes from annual precipitation (mean $1359 \mathrm{~mm}$ per annum). The second site in Sangar, a small town $\left(37^{\circ} 27^{\prime} \mathrm{N}, 48^{\circ} 35^{\prime} \mathrm{E}\right)$ near Rasht, was a closed, shallow (2.4 m depth) water passage $<1 \times 2.5 \mathrm{~km}$. During agricultural activity, a narrow shallow stream of slow-flowing water passes through it for one month (July) a year. Similar to the Rasht site, this site also had access to a regular supply of freshwater from rainfall and shallow muddy water throughout the year. Other areas in Guilan Province were also investigated but no leeches were found. The 2 study areas were separated by $18 \mathrm{~km}$. The

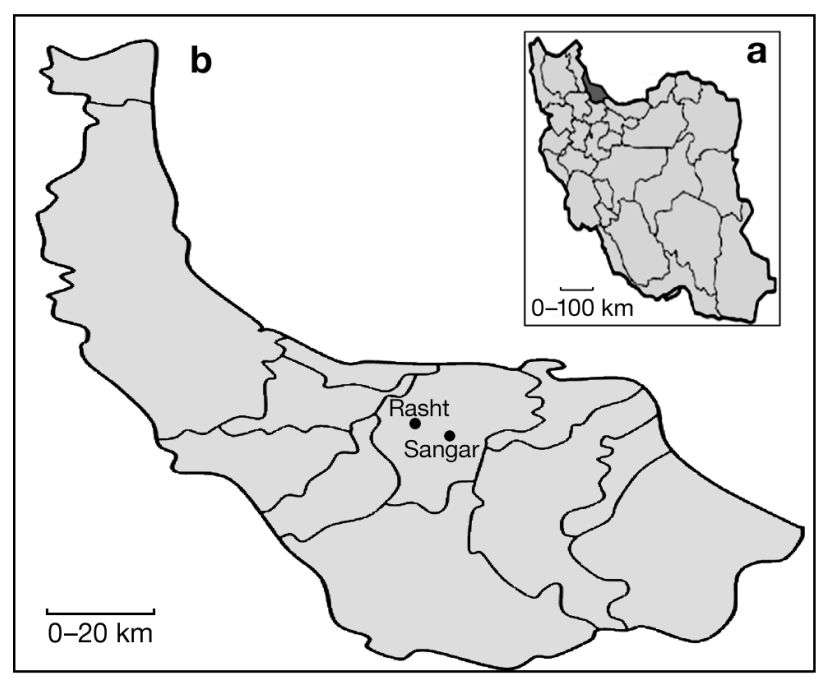

Fig. 1. (a) Location of Guilan Province in the north of Iran (dark grey area). (b) Guilan Province. Black dots indicate study areas (from www.gilanvila.com/gilan_map.html) study areas are near rice fields, and temporary agricultural activities might affect leech habitats during the year, for example, when farmers construct irrigation channels that remain open for a month. The Sangar site did not experience much fluctuation because it was suitably located such that water could pass through it during the month of agricultural activity and there was no need for the farmers to disturb it. The Rasht site, however, was disturbed since channels were dug during the agricultural month to let water flow through.

Sampling and laboratory methods. Both areas were surveyed monthly from November 2008 to October 2009 using a semi-quantitative method (Elliott \& Tullett 1986). Surveys were made in all months; however, no specimens were found in the cold months. Leeches were attracted by disturbing the water and then handcollected for $1 \mathrm{~h}$ to give a simple value for abundance. The 'collecting efficiency' was calculated as the number of leeches collected per hour by a single collector (Demirsoy et al. 2001). Leeches were weighed individually to the nearest $0.01 \mathrm{~g}$ in the laboratory and grouped into 3 classes $(<1,1$ to 5 , and $>5 \mathrm{~g})$, representing hatchlings, juveniles and adults, respectively. No fed leeches were present in this study because they showed no interest in the collector as a potential prey. There was usually a trace of blood in medicinal leeches' digestive tract; however, it was not enough to affect the wet weight measurement and determination of the life cycle stage of the individuals studied.

The major hosts for leeches in both areas were amphibians. Amphibians and surface vegetation were collected by net for $1 \mathrm{~h}$, and the biomass calculated. All data relating to biomass of surface vegetation, leeches and amphibian are relative figures obtained for $1 \mathrm{~h}$ each month and have been compared between different months and stations for the purposes of this study. Dominant amphibians in both study areas included a Bufo sp. and a Rana sp., both of which were collected at the same time as the leeches. Predation of leeches on amphibians was observed during the course of the study, especially in warm months. However, these leeches were not collected because they were fed and did not attack the collector, and thus did not meet the collecting efficiency criteria. Predominant vegetation at both sites included algae, mosses, and common floating pond plants such as duck weed (Lemnaceae), common frogbit Hydrocharis species, waterthread pondweed Potamogeton species, and water nymph Najas species. Vegetation densities were grouped into 2 wet biomass classes of high and low density. During the processing of all samples, care was taken to ensure that surplus water was removed before weighing. Dissolved water oxygen and $\mathrm{pH}$ were measured using a multifunction WTW MULTILINE P4 device. 
Statistical methods. All data were analyzed by SPSS 17.0. Kolmogorov-Smirnov normality tests were applied to test the normal distribution of the data and parametric or nonparametric tests were used as appropriate.

\section{RESULTS}

\section{Physical characteristics of study areas}

In Rasht, the substratum was muddy. Dissolved oxygen showed little change during the year, remaining at 7.75 to $7.98 \mathrm{mg} \mathrm{l}^{-1}$. Air temperatures at both sites showed little difference, $<2{ }^{\circ} \mathrm{C}$. Leeches were most abundant in May/June (at water temperatures of 15 to $23^{\circ} \mathrm{C}$ ). The $\mathrm{pH}$ was almost constant throughout the year (7.2 to 7.3). In Sangar, the same chronological pattern of leech abundance was observed (at water temperatures of 14 to $21^{\circ} \mathrm{C}$ in May/June). The substratum was muddy with a high levels of sedimentation. Dissolved oxygen showed little change during the year (6.84 to $7.26 \mathrm{mg} \mathrm{l}^{-1}$ ). The $\mathrm{pH}$ was almost constant at 7.1 to 7.2 . A $t$-test showed no significance difference in the mean number of leeches in the 2 areas of study ( $\mathrm{p}=0.2, t=1.165)$.

\section{Seasonal variation in leech wet biomass}

Seasonal variation in the mean wet biomass in both study areas is given in Table 1 . The maximum weight of a Hirudo orientalis individual (5.81 g) was obtained at Rasht in September 2009. Sharp reductions in total leech mean wet biomass in Rasht occurred during July 2009 (Fig. 2). The highest mean wet biomass (159.09 g) was obtained at Rasht in June 2009, and the lowest (31.65 g) was obtained at Sangar in October 2009.

There was a significant difference between mean weight (g) of leeches in both study areas (MannWhitney $U=12533.50, \mathrm{p}=0.008$ ), and a significant difference in the mean leech weight $(\mathrm{g})$ in different

Table 1. Hirudo orientalis. Wet weight (g) of leeches from 2 sample sites in northern Iran; no data for December to March

\begin{tabular}{|llllll|}
\hline \multirow{2}{*}{ Month } & \multicolumn{2}{c}{ Rasht } & & \multicolumn{2}{c|}{ Sangar } \\
\cline { 2 - 3 } \cline { 6 - 6 } & Mean \pm SE & Range & & Mean \pm SE & Range \\
\hline Nov 2008 & $2.98 \pm 1.07$ & $1.73-5.29$ & & $2.97 \pm 1.25$ & $1.59-5.14$ \\
Apr 2009 & $0.59 \pm 0.30$ & $0.10-0.99$ & & $0.60 \pm 0.27$ & $0.11-0.97$ \\
May 2009 & $2.38 \pm 1.45$ & $0.18-4.88$ & & $1.43 \pm 1.50$ & $0.11-4.71$ \\
Jun 2009 & $3.13 \pm 1.10$ & $1.01-4.93$ & & $2.61 \pm 1.16$ & $1.12-4.73$ \\
Jul 2009 & $3.40 \pm 1.03$ & $1.33-4.71$ & & $2.62 \pm 0.84$ & $1.44-4.20$ \\
Aug 2009 & $4.00 \pm 1.39$ & $1.83-5.81$ & & $3.63 \pm 1.30$ & $1.62-5.71$ \\
Sep 2009 & $5.40 \pm 0.27$ & $5.02-5.81$ & & $5.19 \pm 0.18$ & $5.01-5.71$ \\
Oct 2009 & $3.43 \pm 0.96$ & $1.81-5.03$ & & $2.87 \pm 1.42$ & $1.09-5.16$ \\
\hline
\end{tabular}

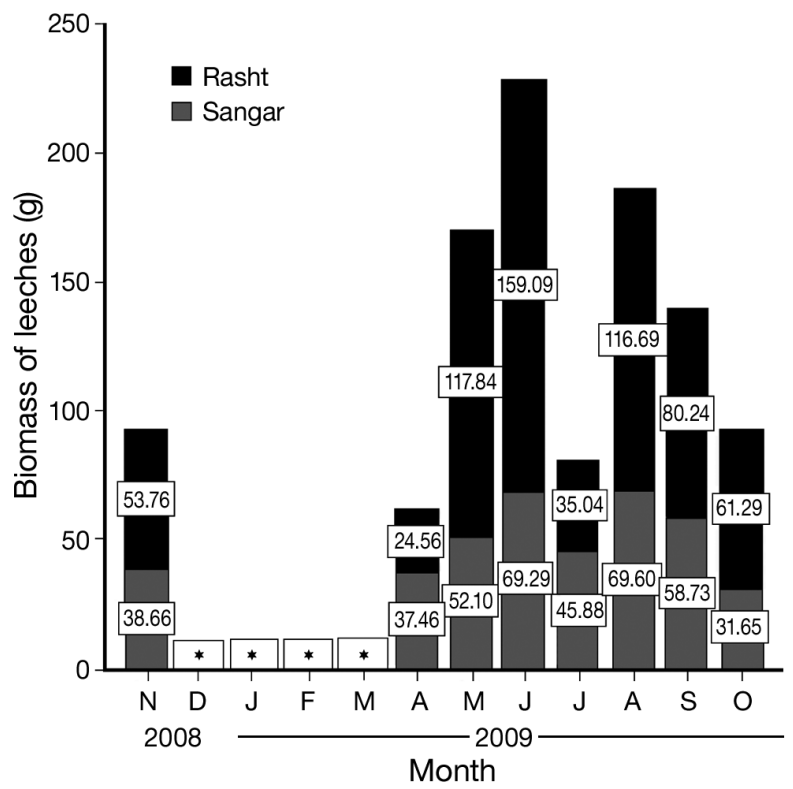

Fig. 2. Hirudo orientalis. Fluctuations in the mean total wet biomass of leeches during all months for both study areas. ${ }^{*}$ : no specimens present

months in both study areas (in Rasht: $\chi^{2}=115.4, \mathrm{p}<$ 0.0005; in Sangar: $\left.\chi^{2}=78.4, p<0.0005\right)$.

\section{Seasonal variation in leech weight classes}

Rasht

In Rasht no uniformity in distribution of the weight classes was observed during the year (Fig. 3a). Juveniles were significantly more frequent than the other classes (mean wet weight of leeches $=3.08 \mathrm{~g}$ ). Hatchlings were most frequent in April and May 2009. In November 2008 and June and July 2009 juveniles were dominant. Adults were most frequent in September $2009\left(\chi^{2}=5.40\right)$.

\section{Sangar}

In Sangar, juveniles were the most frequently observed group throughout the year (Fig. 3b). The hatchlings were dominant in April and May $\left(\chi^{2}=0.60\right)$, while adult leeches were most abundant in August and September $2009\left(\chi^{2}=5.40\right)$. The frequency of juveniles $\left(\chi^{2}=2.79\right)$ was the same as in Rasht with the exception of May 2009. Greater variation in leech weight classes was seen in Rasht. A chi-square test and contingency table showed no significant difference in the total number of adults between the 2 study areas $\left(\chi^{2}=2.64\right.$, $\mathrm{p}=0.45)$, but the difference was significant in some months $\left(\chi^{2}=822.54, \mathrm{p}<0.0005\right)$ (Fig. 3). 

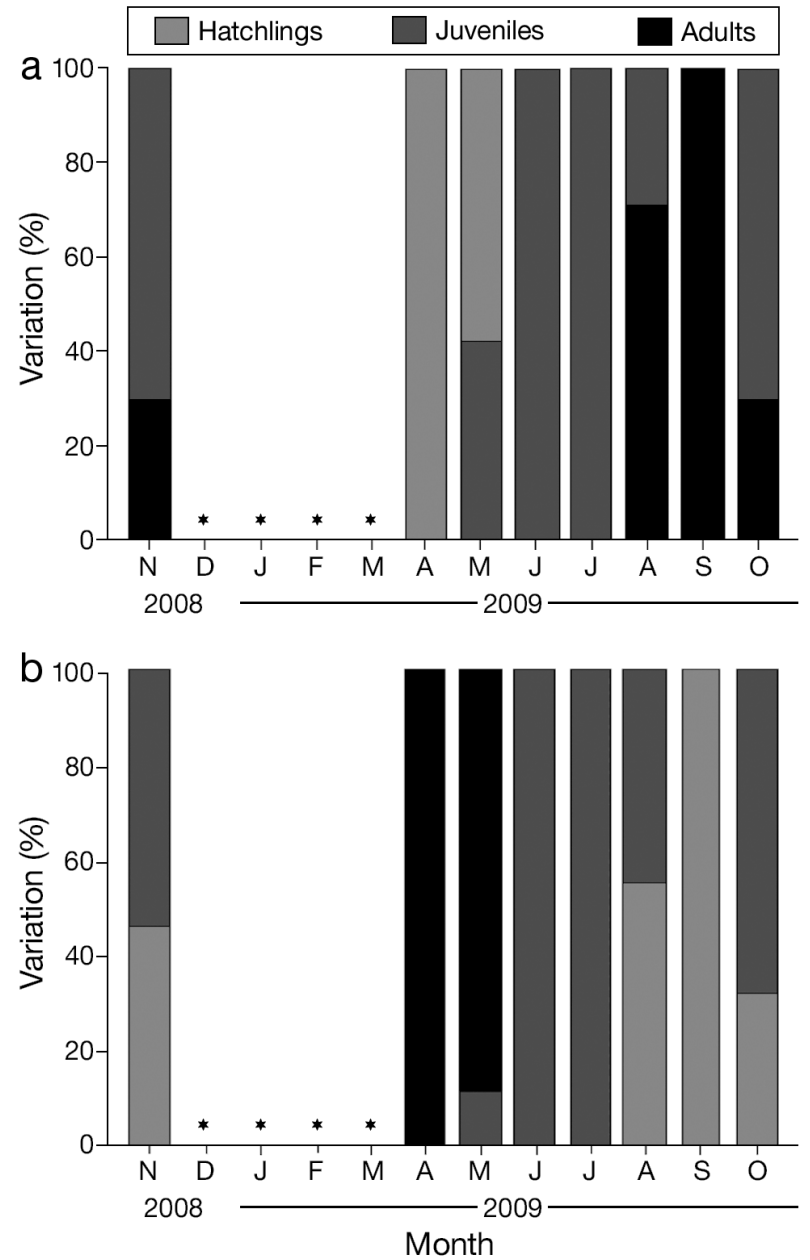

Fig. 3. Hirudo orientalis. Monthly variations in the frequency of life stages in (a) Rasht and (b) Sangar. *: no specimens present

\section{Amphibian density and leech density}

Leech number $(\mathrm{r}=0.942, \mathrm{p}<0.0005)$ and wet biomass $(r=0.88, p<0.0005)$ showed a close and significant correlation with amphibian density in numbers and wet biomass, respectively, and were directly affected by fluctuations in amphibian numbers/biomass (Figs. 4 \& 5). Density of amphibians in Rasht (23.67 ind. $\mathrm{km}^{-2}$ and $620.09 \mathrm{~g} \mathrm{~km}^{-2}$, respectively) was higher than in Sangar (19.16 ind. $\mathrm{km}^{-2}$ and $577.86 \mathrm{~g} \mathrm{~km}^{-2}$, respectively) during all seasons; however, the differences were not significant. Amphibians were abundant throughout the year except in the cold months, including January, February and March, when both areas were covered with snow. Amphibian density showed no significant difference between localities. There was a significant correlation between the densities of leeches and amphibians ( $\mathrm{r}=0.94, \mathrm{p}<0.05)$ (Fig. 4).

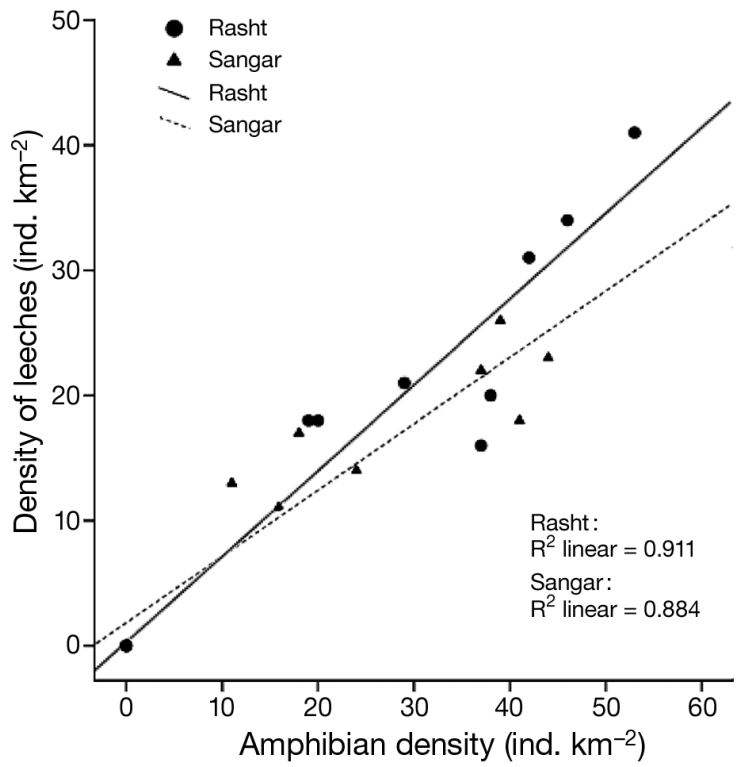

Fig. 4. Correlation between amphibian and leech density

\section{Effect of vegetation biomass on leech biomass}

There was a significant correlation between leech and vegetation biomass in both study areas $(r=0.90$, $\mathrm{p}<0.0005$ ) (Fig. 6a). In Rasht, mean wet biomass of vegetation was $238.77 \mathrm{~g} \mathrm{~km}^{-2}$, which was greater than at Sangar $\left(\chi^{2}=213.19\right)$, but the difference was not significant. Fig. 6b shows that there was a close relationship between amphibian and vegetation biomass fluctuations as determining factors in leech abundance

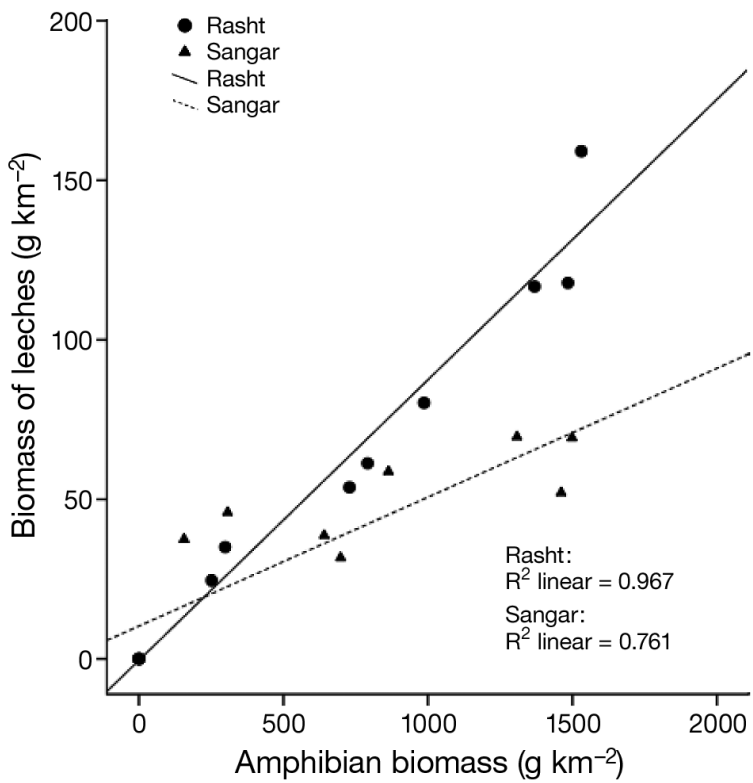

Fig. 5. Correlation between amphibian and leech mean total wet biomass 

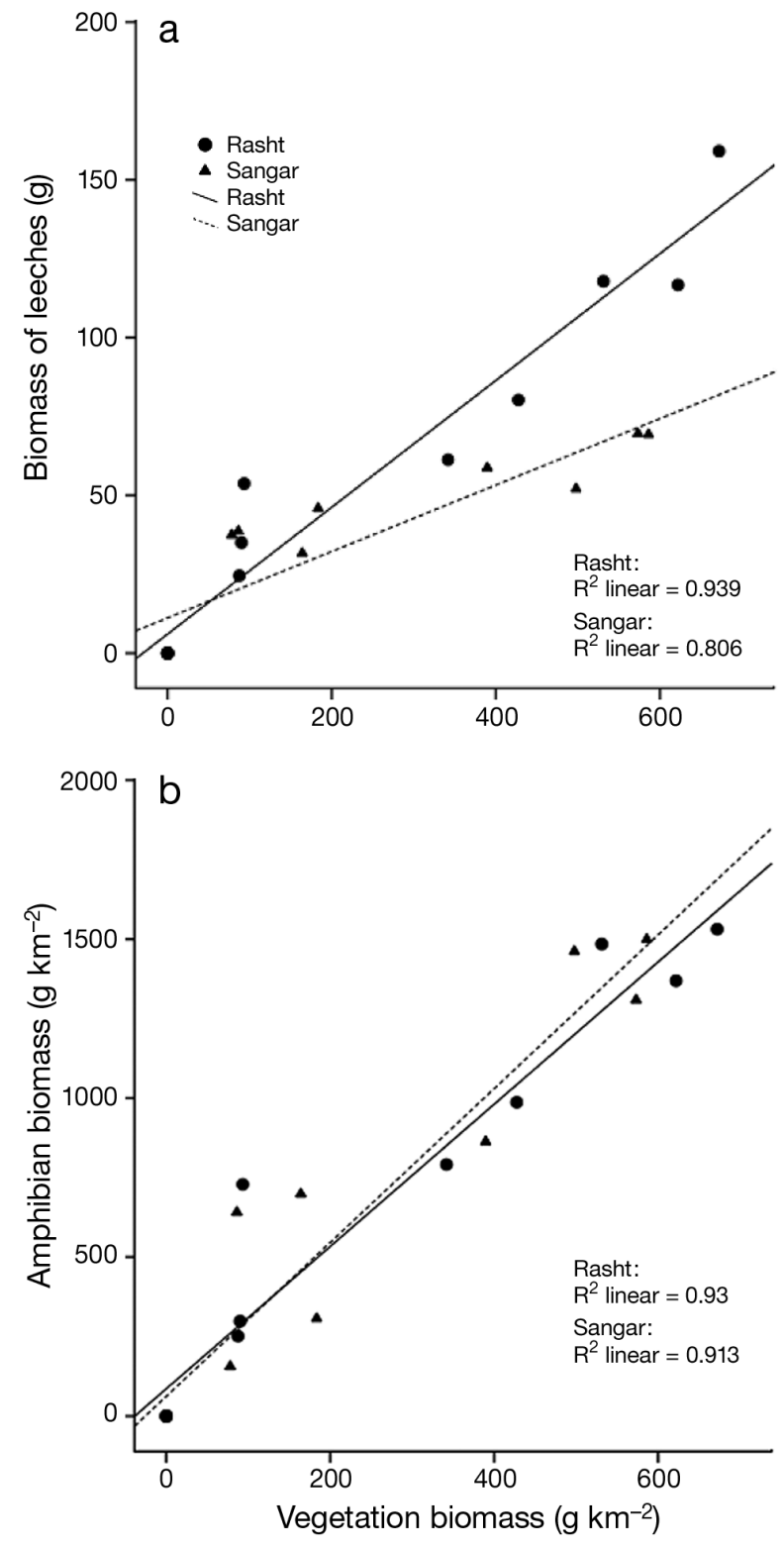

Fig. 6. Correlation between mean total wet biomass of vegetation and (a) Hirudo orientalis and (b) amphibians

(subsequently affecting leech biomass). Vegetation acts as a shelter for both amphibians and leeches. There was a significant correlation between amphibian and vegetation wet biomass $(r=0.95, \mathrm{p}<0.0005)$. Vegetation biomass showed fluctuation during the course of the study in both sampling areas.

\section{Effect of temperature on leech biomass}

No temperature differences were observed between the 2 study areas. Air temperature was found to be a dominant factor affecting the amphibian population density (the only available food source for leeches) and vegetation. Correlation between temperature and total leech biomass is shown in Fig.7. A significant correlation was found between temperature and leech wet biomass $(\mathrm{r}=0.75, \mathrm{p}<0.05)$.

\section{DISCUSSION AND CONCLUSIONS}

To date, no data have been available on seasonal variation in Hirudo orientalis populations in Iran. Results of the present study confirmed the presence of 2 small populations of this species in the Guilan Province. A sharp reduction in total leech mean wet biomass in Rasht occurred during July 2009, when the area was disturbed due to agricultural activities. Hatchlings were predominant in April and May. Demirsoy et al. (2001) showed that the number of leeches in this weight class increases strongly during May and June and reaches a maximum in July. A continuous drop was observed in Rasht after August 2009, associated with low water temperature, reduced amphibian density, and lower vegetation biomass. $H$. orientalis were observed to hibernate during the cold months. Another condition affecting leech density is the amount of rooted vegetation relative to the volume of water (Mann 1962). Small ponds have a large proportion of rooted plants, and the products of their decay lead to a high concentration of humic acids in the water (Tucker 1958). However, in the present study the effect humic acid and its accumulation as a factor affecting the leech community was not measured.

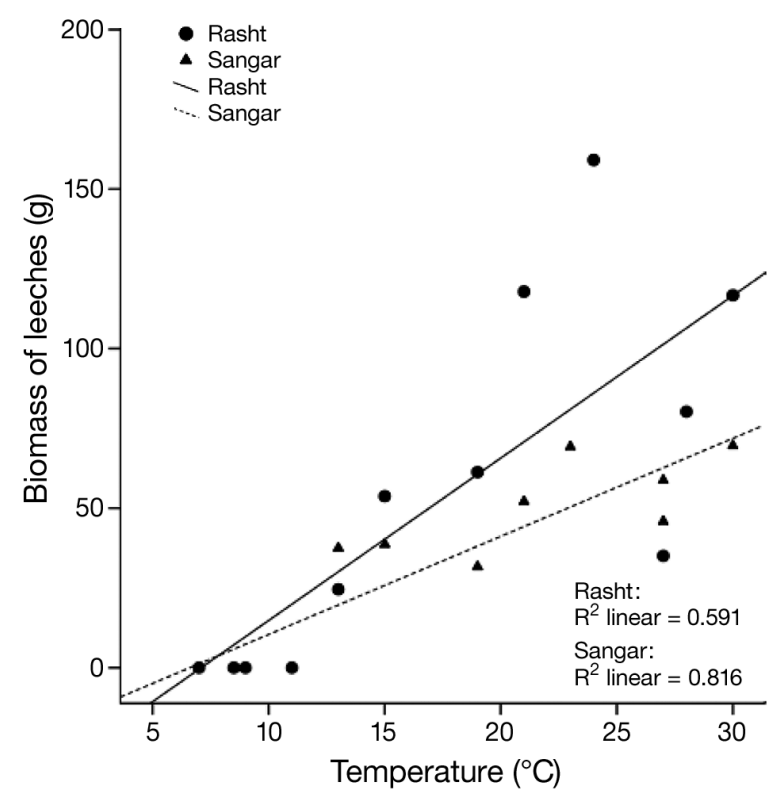

Fig. 7. Hirudo orientalis. Correlation between mean total wet biomass of leeches and temperature for all months 
Vegetation provides shelter and food for tadpoles, which then become prey for leeches in their juvenile and adult stages, as was observed in this study. Furthermore, vegetation provides shelter for leeches, which helps protect them from predators such as ducks. Therefore, surface vegetation increased the chances of leech survival both directly and indirectly. Mean wet biomass of leeches increased significantly with an increase in vegetation biomass.

The dissolved oxygen concentration and the $\mathrm{pH}$ of water bodies are important parameters that determine the spatial and temporal distribution of aquatic organisms, particularly of fish fauna (Araoye 2009). The most important source of oxygen is photosynthesis by aquatic plants (Boyd 1979). Vegetation would, therefore, be important for the survival of amphibians in the still waters of Rasht and Sangar.

The role of air temperature was similar to that of vegetation. Fluctuations in air temperature had a considerable effect on the mean total biomass of leeches in the present study. Aston \& Brown (1975) also recognized temperature as an important factor in the fluctuation of leech biomass. The sharp reduction in the biomass of leeches in our study in July 2009, despite temperatures of 24 to $27^{\circ} \mathrm{C}$, was probably due to disturbance of the leech habitat caused by agricultural activity. The high frequency of hatchings in April 2009 reflected the high reproductive rate during the previous warm months. A significant increase in juveniles was observed in July 2009. In general, in Rasht, the frequency of adults was significantly higher than in Sangar, likely related to more favorable conditions in Rasht (amphibian availability, vegetation). Similar results were seen for leech mean total wet biomass.

Generally, amphibian density and biomass had major effects on seasonal variation in leeches, although medicinal leeches usually feed on mammalian blood (Merilä \& Sterner 2002). The long-held view about them in the literature confirms this, but field observations and recent serological investigations (Wilkin \& Scofield 1990, Keim 1993) indicate that (because of their regular availability) amphibians were an important source of food for medicinal leeches. Only the 2 species of amphibians mentioned were observed during our study, and direct predation and feeding on these amphibians by leeches was recorded, but the role of vegetation as a factor affecting both amphibians and leeches is also considerable. It should also be noted that amphibian and vegetation biomass are greatly affected by the major forcing factor in both ecosystems, i.e. temperature. Our knowledge of the ecology of leeches is incomplete, but the presence or absence of an appropriate host organism appears to be an important factor influencing leech distribution and abundance (Mann 1962).
Acknowledgements. The authors thank Dr. Sari for his advice and H. Salehi, M. Parsa, and A. Kazemi for their help. We also thank the Research Affairs Office of the University of Tehran for financial support. We are grateful to Lucidus Consultancy for critical comments and English editing of the earlier version of the manuscript.

\section{LITERATURE CITED}

Araoye PA (2009) The seasonal variation of $\mathrm{pH}$ and dissolved oxygen $\left(\mathrm{DO}_{2}\right)$ concentration in Asa lake Ilorin, Nigeria. Int J Phys Sci 4:271-274

Aston RJ, Brown DJA (1975) Local and seasonal variations in populations of the leech Erpobdella octoculata (L.) in a polluted river warmed by condenser effluents. Hydrobiologia 47:347-366

Boyd CE (1979). Water quality in warm water fish ponds, 1st edn. Craftmaster Printers, Auburn, AL

Demirsoy A, Kasparek M, Akbulut A, Durmuş Y, Akbulut N, Çalşkan M (2001) Phenology of the medicinal leech, Hirudo medicinalis L., in north-western Turkey. Hydrobiologia 462: $19-24$

> Elliott JM, Tullett PA (1986) The effects of temperature, atmospheric pressure and season on the swimming activity of the medicinal leech, Hirudo medicinalis (Hirudinea, Hirudinidae), in a Lake Distict tarn. Freshw Biol 16:405-415

> Enguang T (2008) Progress in the study of ecology, zoogeography, group, control repellent and medical usage of Hirudinea in China. Acta Ecol Sin 28:6272-6281

Grosser C, Pešić V (2006) On the diversity of Iranian leeches (Annelida: Hirudinea). Arch Biol Sci 58:21-24

Kalninsš M (2006) The distribution and ecology of medicinal leech Hirudo medicinalis Linnaeus, 1758 (Hirudinea: Arhynchobdellae) in Latvia. Acta Biol Univ Daugavp 6(1-2): 91-93

Kasparek M, Demirsoy A, Akbulut A, Akbulut N, Çalşkan M, Durmuş, Y (2000) Distribution and status of the medicinal leech (Hirudo medicinalis L.) in Turkey. Hydrobiologia 441: $37-44$

Keim A (1993) Studies on the host specificity of medicinal blood leech (Hirudo medicinalis). Parasitol Res 79:251-255

Mann KH (1962) Leeches (Hirudinea) their structure, physiology, ecology and embryology. Pergamon Press, New York, NY

Merilä J, Sterner M (2002) Medicinal leeches (Hirudo medicinalis) attacking and killing adult amphibian. Ann Zool Fenn 39:343-346

Trontelj P, Utevsky SY (2005) Celebrity with a neglected taxonomy: molecular systematics of the medicinal leech (genus Hirudo). Mol Phyl Evol 34:616-624

Trontelj P, Sotler M, Verovnik P (2004) Genetic differentiation between two species of the medicinal leech, Hirudo medicinalis and the neglected $H$. verbana, based on random amplified polymorphic DNA. Parasitol Res 94:118-124

> Tucker DS (1958) The distribution of some freshwater invertebrates in ponds in relation to annual fluctuations in the chemical composition of the water. J Anim Ecol 27:105-123

> Utevsky SY, Trontelj P (2005) A new species of the medicinal leech (Oligochaeta, Hirudinida, Hirudo) from Transcaucasia and an identification key for the genus Hirudo. Parasitol Res 98:61-66

> Wilkin PJ, Scofield AM (1990) The use of a serological technique to examine host selection in a natural population of the medicinal leech, Hirudo medicinalis. Freshw Biol 23:165-169

Wilkin PJ, Scofield AM (1991) Growth of the medicinal leech, Hirudo medicinalis, under natural and laboratory conditions. Freshw Biol 25:547-553

Submitted: May 21, 2010; Accepted: December 6, 2010

Proofs received from author(s): February 10, 2011 